\title{
NURSES' KNOWLEDGE AND PRACTICE REGARDING INTRAVENOUS THERAPY IN A TEACHING HOSPITAL, BHARATPUR
}

Sandhya Lamsal ${ }^{1, *}$, Rosy Shrestha ${ }^{1}$

School of Nursing, Chitwan Medical College, Bharatpur, Nepal

\section{Received: 04 May, 2018 \\ Accepted: 16 Jan, 2019 \\ Published: 31 Mar, 2019 \\ Key words: Intravenous Therapy; Knowl- edge; Nurses; Practice. \\ *Correspondence to: Sandhya Lamsal, School of Nursing, Chitwan Medical College, Bharatpur, Nepal. Email: me.sandhya20@gmail.com \\ Citation \\ Lamsal S, Shrestha R. Nurses' knowl- edge and practice regarding intravenous therapy in a teaching hospital, Bharat- pur. Journal of Chitwan Medical College. 2019; 9 (27): 13-19.}

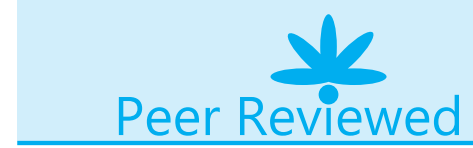

\section{INTRODUCTION}

Intravenous therapy (IVT) is the procedure that needs manual skills, professional competency, knowledge about the anatomy and physiology of vascular system. It is used more frequently for administration of different drugs, fluids, blood, nutrition for sampling and other purposes. ${ }^{1}$ In clinical setting of hospital, nurses are believed to be accountable and responsible for handling and managing patient with it. $^{2}$

About 25 million people worldwide receive IV therapy by means of peripheral cannula yearly. ${ }^{3-4}$ Fluid and electrolyte replacement through IVT is the important component for critical patient to maintain hemodynamic status. Thrombophlebitis is a common complication associated with IVT due to the infection and responsible reason for increased morbidity and mortality. ${ }^{5}$

Various complications related to IVT should be prevented by health worker especially nurses. To avoid these complications, the nurse needs to have competence in knowledge as well as practice of intravenous therapy. Trained nurses have adequate 
knowledge of prevention of risk factors of infections and skillful to care for patient with peripheral intravenous. ${ }^{6}$ Knowledge and practice regarding IVT among nurses is important key component to provide quality care to the patient with IVT and prevent complications related to IVT. ${ }^{7}$

Very few studies were addressed regarding this issue in hospital setting previously. ${ }^{2,8}$ So, investigator was interested to conduct this study to findout the knowledge and practice regarding intravenous therapy among nursing personnel.

\section{METHODS}

This study was conducted in Chitwan Medical College Teaching Hospital (CMCTH), Bharatpur during month of October 2016 with 177 nurses who met the inclusion criteria like all the registered nurses $(\mathrm{N}=354)$ working at $\mathrm{CMC}-\mathrm{TH}$ with at least 3 month professional experience for assessing the knowledge and among them only $30 \%$ of sample size $(n=53)$ nurses for assessing the practice of IVT after getting approval from Institutional Review Committee (IRC$\mathrm{CMC}$ ) and informed consent from each respondents for this study.

A cross-sectional study design was used. Systematic random sampling technique was adopted. First of all required sample size was calculated by using $n=$ $\mathrm{z} 2 \mathrm{pq} / \mathrm{d} 2$ then Kth interval was identified by dividing sample frame/population 354 by 177 (sample size) so kth value was found to be 2 then first random sample was drawn by lottery method and selected individual sample was added with kth value 2 till required sample size $(n=177)$ was reached. The data was collected by using semi-structured (26 items) self-administered questionnaire for assessing knowledge and observational checklist (24 items) for observing practice of nurses working in different units of CMCTH like general area (ENT, Gynae, Tropical, Nephro, Ortho, Pediatric, Paying, Psychiatric, Surgical) and Critical area (CCU, ER, HDU, Hemodialysis, MICU, NEURO, NICU, OT, PICU, Post-op, SICU, Respiratory) were selected. Data was analyzed for descriptive statistics (frequency, percentage, mean, and standard deviation) and inferential statistics (chi-square). Prior to measure association level of knowledge and practice was classified based on Mean \pm SD $(11 \pm 2.43)$ for knowledge and Mean \pm SD $(20 \pm 1.75)$ for practice regarding IVT.

\section{RESULTS}

\section{Demographic Information of Respondents}

In this study (table 1), mean age of the respondent was $22.7 \pm 2.66$ and $50.3 \%$ of respondents were in the age equal and more than 23 years old, residing in urban region (91.0\%), having religion as Hindu (93.8\%) and with ethnicity of Brahmin/ Chhetri (77.9\%), graduated from private institution (85.3\%), $\mathrm{PCL}$ nursing qualification $(81.9 \%)$, staff nurse as professional designation (84.7\%), working in general ward (57.6\%), less than one year experience (38.6\%) and not participated in-service education on IVT (84.7\%).

Table 1: Respondents' Socio-demographic Characteristics

$\mathrm{n}=\mathbf{1 7 7}$

\begin{tabular}{|l|l|l|}
\hline \multicolumn{1}{|c|}{ Variable } & No. & $\%$ \\
\hline Age groups (in years) & \multicolumn{2}{l|}{} \\
\hline$<23$ & 88 & \\
\hline$\geq 23$ & 89 & 49.7 \\
\hline Mean $\pm S D=22.7 \pm 2.66$ & \multicolumn{2}{l|}{} \\
\hline Place of residence & 159 & 50.3 \\
\hline Urban & 18 & 91.0 \\
\hline Rural & & 9.0 \\
\hline Religion & 166 & \\
\hline Hindu & 11 & 93.8 \\
\hline Non hindu & & 6.2 \\
\hline
\end{tabular}




\begin{tabular}{|l|l|l|}
\hline Ethnicity & & \\
\hline Brahmin/Chhetri & 138 & 77.9 \\
\hline Dalit/janjati & 39 & 22.1 \\
\hline Educational institute & & \\
\hline Government & 26 & 14.7 \\
\hline Private & 151 & 85.3 \\
\hline Professional qualification & & \\
\hline Bachelor of nursing & 17 & 9.6 \\
\hline Proficiency certificate level & 145 & 81.9 \\
\hline B.sc. nursing & 15 & 8.5 \\
\hline Professional designation & & \\
\hline Staff nurse & 150 & 84.7 \\
\hline Senior staff nurse & 27 & 15.3 \\
\hline Clinical area & & \\
\hline General * & 102 & 57.6 \\
\hline Critical** & 75 & 43.4 \\
\hline Professional experience & & \\
\hline Less than year & 69 & 38.6 \\
\hline One year to less than 2 year & 52 & 29.4 \\
\hline Two year or more & 56 & 32.0 \\
\hline In service education on IV therapy & & \\
\hline Yes & 27 & 15.3 \\
\hline No & 150 & 84.7 \\
\hline
\end{tabular}

* ENT, Gynae, Tropical, Nephro, Ortho, Pediatric, Paying, Psychiatric, Surgical

** CCU, ER, HDU, Hemodylis, MICU, NEURO, NICU, OT, PICU, Post-op, SICU, Respiratory.

\section{Respondent's Level Knowledge and Practice regarding IV Therapy}

Table 2 shows about more than half of respondents (50.9\%) had inadequate knowledge regarding IV therapy whereas less than half of the respondents (49.1\%) had adequate knowledge regarding IV therapy and Table 3 shows about two third of respondents $(66.1 \%)$ had unsatisfactory level of IV therapy practice whereas only (33.9\%) of the respondents had satisfactory in their practice in relation to IV therapy.

Table 2: Respondents' Level of Knowledge on Intravenous Therapy

\begin{tabular}{|l|l|l|}
\hline \multicolumn{1}{|c|}{ Level of Knowledge } & No. & $\%$ \\
\hline Adequate $($ mean $>11)$ & 87 & 49.1 \\
\hline Inadequate $($ mean $\leq 11)$ & 90 & 50.9 \\
\hline Total & 177 & 100.0 \\
\hline Mean \pm SD (11+2.43); Possible scores-0-16
\end{tabular}

Table 3: Respondents' Level of Practice on Intravenous Therapy $\mathrm{n}=177$

\begin{tabular}{|l|l|l|}
\hline \multicolumn{1}{|c|}{ Level of Practice } & Frequency & $\%$ \\
\hline Satisfactory $($ mean $>20)$ & 18 & 33.9 \\
\hline Unsatisfactory $($ mean $\leq 20)$ & 35 & 66.1 \\
\hline Total & 53 & 100.0 \\
\hline
\end{tabular}

Mean $\pm S D$ (20 \pm 1.75$)$; possible scores-0-24

Table 4 shows that significant influencing variables of level of knowledge regarding IV therapy were age group $(P=0.012)$, professional qualification $(P=0.001)$, professional designation $(P=0.005)$, professional experience $(P=0.001)$ and in-service education training $(P=0.033)$ Whereas Table 5 shows that significant influencing variables of level of practice regarding IV therapy were professional qualification $(P=0.020)$, and professional designation $(P=0.043)$. 
Table 4: Association between Respondents Level of Knowledge regarding IV Therapy and Selected Variables

$(n=177)$

\begin{tabular}{|l|l|l|l|l|}
\hline \multirow{2}{*}{ Variables } & \multicolumn{2}{|c|}{ Level of Knowledge } & \multirow{2}{*}{ X 2} & \multirow{2}{*}{-value } \\
\cline { 2 - 5 } & Adequate & Inadequate & & \\
\hline Age Group(in years) & & & & $0.012^{*}$ \\
\hline$<23$ & $26(38.8 \%)$ & $41(61.2 \%)$ & 6.255 & \\
\hline Place of residence & $64(58.2 \%)$ & $46(41.8 \%)$ & & \\
\hline Urban & & & & 0.943 \\
\hline Rural & $82(50.9 \%)$ & $79(49.1 \%)$ & 0.15 & \\
\hline Religion & $8(50.0 \%)$ & $8(50.0 \%)$ & & $0.106 \#$ \\
\hline Hindu & & & & \\
\hline Non-hindu & $87(52.4 \%)$ & $79(47.6 \%)$ & 2.608 & \\
\hline Ethnic group & $3(27.3 \%)$ & $8(72.7 \%)$ & & 0.305 \\
\hline Brahmin/Chhetri & & & & \\
\hline Dalit/Janajati & $73(52.9 \%)$ & $65(47.1 \%)$ & 1.054 & \\
\hline Educational institute & $17(43.6 \%)$ & $22(56.4 \%)$ & & 0.604 \\
\hline Government & & & & \\
\hline Private & $12(46.2 \%)$ & $14(53.8 \%)$ & 1.269 & \\
\hline Professional qualification & $17(51.7 \%)$ & $73(48.3 \%)$ & & \\
\hline PCL level & & & & \\
\hline Bachelor level & $82(56.6 \%)$ & $63(43.4 \%)$ & 10.442 & $0.001^{*}$ \\
\hline Professional designation & $8(51.7 \%)$ & $24(48.3 \%)$ & & \\
\hline Staff nurse & & & & \\
\hline Senior staff nurse & $83(55.3 \%)$ & $67(44.7 \%)$ & 7.917 & $0.005^{*}$ \\
\hline Clinical area & $7(25.9 \%)$ & $20(74.1 \%)$ & & \\
\hline General & & & & \\
\hline Critical & $48(47.1 \%)$ & $54(52.9 \%)$ & 1.382 & 0.24 \\
\hline Professional experience & $42(56.0 \%)$ & $33(44.0 \%)$ & & \\
\hline$<2$ years & $54(63.5 \%)$ & $31(36.5 \%)$ & 10.524 & $0.001^{*}$ \\
\hline$\geq 2$ years & $36(39.1 \%)$ & $56(60.9 \%)$ & & \\
\hline In-Service education & & & & \\
\hline Yes & $24(66.7 \%)$ & $12(33.3 \%)$ & & \\
\hline No & $66(46.8 \%)$ & $75(53.2 \%$ & & \\
\hline
\end{tabular}

* Significant $P$ value at $<0.05$; *Pearson Chi square, \# Yates Correction

\section{DISCUSSION}

The current study examined the knowledge and practice regarding IVT among nurses of CMCTH, Bharatpur. This study found that nurses' have inadequate knowledge and unsatisfactory practice on IVT. The mean percentage knowledge on IVT was $68.75 \%$. This finding was supported by a study conducted by Vicdan (2013) in which average mean $\%$ knowledge score was $66.7 \% .^{8}$ Similarly, it was found that only $49.1 \%$ respondents had adequate 
Table 5: Association between Respondents Level of Practice on IV Therapy and Selected Variables

\begin{tabular}{|c|c|c|c|c|}
\hline \multirow{3}{*}{ Variable } & \multicolumn{4}{|c|}{$n=53$} \\
\hline & \multicolumn{2}{|c|}{ Level of Practice } & \multirow{2}{*}{$x^{2}$} & \multirow{2}{*}{$p$-value } \\
\hline & Satisfactory & Unsatisfactory & & \\
\hline \multicolumn{5}{|l|}{ Age group (in years) } \\
\hline$<23$ & $13(56.5 \%)$ & $10(43.5 \%)$ & 1.641 & 0.2 \\
\hline$\geq 23$ & $22(73.3 \%)$ & $8(26.7 \%)$ & & \\
\hline \multicolumn{5}{|l|}{ Place of residence } \\
\hline Urban & $34(65.4 \%)$ & $18(34.6 \%)$ & 0.524 & 0.469 \\
\hline Rural & $1(100.0 \%)$ & $0(0 \%)$ & & \\
\hline \multicolumn{5}{|l|}{ Religion } \\
\hline Hindu & $30(65.2 \%)$ & $16(34.8 \%)$ & 0.105 & 0.746 \\
\hline Non-hindu & $3(71.3 \%)$ & $2(28.7 \%)$ & & \\
\hline \multicolumn{5}{|l|}{ Ethnic group } \\
\hline Brahmin/Chhetri & $29(69.0 \%)$ & $13(31.0 \%)$ & 0.817 & 0.366 \\
\hline Dalit/Janajati & $6(53.6 \%)$ & $5(46.4 \%)$ & & \\
\hline \multicolumn{5}{|l|}{ Educational institute } \\
\hline Government & $7(70.0 \%)$ & $3(30.0 \%)$ & 0.086 & 0.769 \\
\hline Private & $28(65.7 \%)$ & $15(34.3 \%)$ & & \\
\hline \multicolumn{5}{|c|}{ Professional qualification } \\
\hline PCL level & $31(73.8 \%)$ & $11(26.2 \%)$ & 5.45 & 0.020\# \\
\hline Bachelor level & $4(36.4 \%)$ & $7(63.6 \%)$ & & \\
\hline \multicolumn{5}{|c|}{ Professional designation } \\
\hline Staff nurse & $30(71.4 \%)$ & $12(28.6 \%)$ & 3.622 & $0.04 *$ \\
\hline Senior staff nurse & $5(45.5 \%)$ & $6(54.5 \%)$ & & \\
\hline \multicolumn{5}{|l|}{ Clinical area } \\
\hline General & $7(50.0 \%)$ & $7(50.0 \%)$ & 2.182 & 0.14 \\
\hline Critical & $28(72.0 \%)$ & $11(28.0 \%)$ & & \\
\hline \multicolumn{5}{|c|}{ Professional experience } \\
\hline$<2$ years & $18(78.0 \%)$ & $5(22.0 \%)$ & 2.707 & 0.1 \\
\hline$\geq 2$ years & $17(57.0 \%)$ & $13(43.0 \%)$ & & \\
\hline \multicolumn{5}{|l|}{ In-Service education } \\
\hline Yes & $12(66.7 \%)$ & $6(33.3 \%)$ & 0.05 & 0.9 \\
\hline No & $23(65.8 \%)$ & $12(34.2 \%$ & & \\
\hline
\end{tabular}

* Significant $P$ value at $<0.05 ; *$ Pearson Chi square, \# Yates Correction

knowledge on IVT while a study conducted in Dhaka city by Hossain, (2016) found that $50.7 \%$ had good knowledge on IVT. ${ }^{9}$

In this study, about two third of respondents (66.1\%) had unsatisfactory practice ( $\leq 20$ mean score ie. $80 \%$ score) on IV therapy. This also explains there is plenty of variation among nurses' practice on IV therapy. Similar research was presented by Gunes \& Celik (2002), Hadway (1999) found average practice score of $51 \%$, more than two third of practice score i.e. $68 \%$ and nurses were not practicing appropriately regarding caring and maintaining peripheral intravenous canulation respectively. ${ }^{2,10}$ 
In this study, about two third of respondents (66.1\%) had unsatisfactory practice ( $\leq 20$ mean score ie. $80 \%$ score) on IV therapy. This also explains there is plenty of variation among nurses' practice on IV therapy. Similar research was presented by Gunes \& Celik (2002), Hadway (1999) found average practice score of $51 \%$, more than two third of practice score i.e. $68 \%$ and nurses were not practicing appropriately regarding caring and maintaining peripheral intravenous canulation respectively. ${ }^{2,10}$

The influencing factors to level of knowledge on IVT were age, professional qualification, professional experience, professional designation and inservice education in which more than half of the respondents (58.2\%) belonged to equal and more than 23 years had adequate knowledge. In this study bachelor level nurses had less (51.7\%) knowledge on IVT than PCL nursing, senior staff nurse had less (25.9\%) adequate knowledge on IVT than staff nurses $(55.3 \%), \geq 2$ years professional experienced have less (39.1\%) adequate knowledge on IVT than $<2$ years professional experienced ones $(63.5 \%)$ and not getting in-service education on IVT $(46.8 \%)$ than participated in in-service education had adequate knowledge on IVT. The study done in Orrisa by Bijayalaxmi (2010) supported this finding in which less than 1 year professional experience (38.6\%) had adequate knowledge on IVT than more than 2 years (29.4\%) whereas B.Sc. nursing qualification were more knowledgeable than PCL Nursing nurses that was contradictory to this study findings. ${ }^{11}$

Study conducted by Vicdan (2013) supported this study finding in which $88.8 \%$ of nurses having training on IVT were more knowledgeable than those who do not have. 8 This signifies the importance of in-service education training for nurses. The results of the study show that level of practice is affected by qualification and designation on IVT. This finding was supported by Kagel \& Rayan (2004). ${ }^{12}$

The study was conducted only on the private hospital in Chitwan, so the finding of the study could not be generalized in other setting like government and other hospital.

\section{CONCLUSION}

It is concluded that nurses' working at CMCTH had inadequate knowledge and unsatisfactory practice on IVT. The influencing factors for level of knowledge are age, professional qualification, professional designation, professional experience and in-service education and the level of practice are professional experience and professional designation. As both level of knowledge and practice is inadequate among nurses, it is recommended to have refresher training for experienced nurse and proper mentorship for inexperience nurse. In addition, Health care providers are accountable for safe and quality care delivery to the patients, so, they should be well resourced and enough trained. Furthermore, private hospital administration should emphasize on refresher training for senior nurses and qualified nurse to fulfill the practice protocols, so that the quality care can be provided.

\section{REFERENCES}

1. Qamar Z, Afzal Muhammad, Kousar R, Waqas A, Gilani SA. Assess nurses knowledge and practice towards care and maintenance of peripheral intravenous cannulation in services hospital Lohore, Pakistan. Saudi J. Med. Pharm. Sci. 2017; 3(6B): 608-14. http://scholarsmepub.com/wpcontent/uploads/2017/07/SJMPS-36B608-614. pdf

2. Gunes A, Celik SS. Knowledge and practices of nurses concerning intravenous potassium administration in a Turkish hospital. Aust J Adv Nurs. 2014; 32(1): 16-22.https://pdfs. semanticscholar.org/7517/9ba45ba6557cf1075 88a6951de470b4e276a.pdf

3. Maki D, Ringer M. Risk factor for infusion- related phlebitis with small peripheral venous catheter. Ann Intern Med. 1991; 114: 845-854. https:// www.ncbi.nlm.nih.gov/pubmed/2014945

4. Angeles T. Barbonw, M. Infiltration and Phlebitis: assessment, management, and documentation. J Home Health Care Practice. 1994;16-21. https:// doi.org/10.1177/108482239400700107

5. Fernandes SL. Effectiveness of information booklet on intravenous infusion on knowledge of staff nurses in selected hospitals of Mangalore. IJSR. 2014, 3(7):346-347. 
6. Lundgren A, Ek AC, Wahren LK. Handling and control of peripheral intra venous lines. J Adv Nur. 1998; 27(5): 897-904. https://www.ncbi. nlm.nih.gov/pubmed/9637314

7. Singh R, Bhandary S, Pun KD. Peripheral intravenous catheter related phlebitis and its contributing factors among adult population at KU Teaching Hospital. KUMJ. 2008; 6(4): 443-447.https://www.ncbi.nlm.nih.gov/ pubmed/19483423

8. Vicdan AK. Evaluation of knowledge on intravenous fluid therapy of the nurses. EJRE; 2014: 135-138. http://iassr2.org/rs/020320.pdf

9. Hossain AM, Hasan MIA, Haque MM. Assessment of the level of knowledge and practice on intravenous cannulization among staff nurses of selected tertiary care hospital in Dhaka City. Journal of Nursing. 2016; 4(5): 1-5. https:// medcraveonline.com/MOJPH/MOJPH-04-00095. pdf

10. Hadaway LC. Developing an interactive education and trainning program. Journal of Intravenous Nursing. 1999; 22(2):87-93. https://www.ncbi. nlm.nih.gov/pubmed/10418412

11. Bijayalaxmi B, Urmila A, Prasad PS. Knowledge of staff nurses regarding intravenous catheter related infrctions working in Orissa. The Nursing Journal of India. 2010; 3: 1-5. https://www.ncbi. nlm.nih.gov/pubmed/23520815

12. Kagel EM, Rayan GM. Intravenous catheter complications in the hand and forearm. The Jorunal of Trauma, Injury, Infection and Critical Care. 2004; 123-127. https://www.ncbi.nlm.nih. gov/pubmed/14749578 